\title{
Social capital: is it good for your health? Issues for a public health agenda
}

For two decades governments around the world have put economic issues at the top of their policy agendas. As a result the search for economic growth has become our holy grail in the final decades of this millennium. The assumption has been that if it's good for the economy then it must be good for the rest of society. Ironically, in public health policy in recent years there has been an increasing acceptance that the determinants of health and well being are complex and reflect a mix of economic, environmental, social, biological, and genetic factors. ${ }^{1}$ Perhaps as a reaction to the overwhelming dominance of economic considerations in public policy debates, there has been a growing emphasis on social determinants of health and well being. This emphasis is to be welcomed but it also challenges the public health community to grapple with the complex way in which social factors interact with economic ones.

Pursuing a social agenda in a world dominated by neoliberal assumptions about the primacy of the needs of the economy has not proved easy for health advocates. However, the emergence of widespread interest in the notion of social capital offers some hope. This interest, in itself, reflects disillusionment with economic dominance in public policy decision making. The dominance is perceived as having contributed to social dislocation and disharmony in many countries, as expressed in rising crime rates, increased social tension between groups, growing inequities, a decline in the quality of relations between citizens, growing mistrust in civic institutions, and a general decline in community spirit. The increased interest in social capital provides an opportunity for the public health community to advance social agendas that have been evident in public health for some time but have not captured popular or political imaginations as much as would be desirable. It is also a means of challenging the individualistic agendas of medicine and neo-liberalism. Seizing the opportunity will require a development of epidemiological and theoretical thinking about the links between social capital, economic development, and health.

A fundamental issue is defining and understanding social capital. The term can easily become a cliched one that people use uncritically without due regard to the underlying ideological and theoretical implications of its use. Despite this, it is possible to discern a broad agreement in the burgeoning literature that social capital concerns the levels of social and civic trust, the presence of both thick and thin, or embedded and autonomous networks and that these factors lead to coordination and cooperation for mutual benefit. Beyond this the picture is far more muddled. Those on the right of the political spectrum see social capital as an opportunity to argue for a withdrawal of the state from welfare and social provisions. Those more towards the left argue that state support is crucial to the accumulation of social capital. Such varied interpretations mean the mechanisms by which social capital is beneficial for health are disputed. A more progressive interpretation of social capital calls for the creation of health promoting communities through a process of mutual re-inforcement of the social and economic. The longitudinal work of the North American sociologist Putnam ${ }^{2}$ on the importance of social cohesiveness to the function of regional governments in Italy was crucial in starting the debate about the relation of levels of social capital to economically and socially suc- cessful societies. His work has been extremely influential in the development of thinking about social capital but has also been criticised. One commentator has gone so far as to say: "The current literature on social capital is very confusing, lacking both terminological precision and theoretical rigour". ${ }^{3}$ This confusion and lack of rigour is perhaps not surprising given the complexity and subjectivity of the fundamental building blocks of social capital such as participation, trust, networks, and cooperation. There are also very different theoretical understandings about the means by which they will have an impact on determinants of health such as inequity and poverty. For some time commentators have called for a greater emphasis on theoretical consideration in public health and health promotion. ${ }^{4}$ Social capital provides a great opportunity for health promoters to flex their theoretical muscles in coming to grips with the social elements of health determinants and health promotion. An important first step is to distinguish different types of social capital (for instance that generated by family and kinship compared with that from associational life or from the links that connect different groups within society). ${ }^{6}$

A hint of the complexities involved is provided by a brief consideration of some of the potential pitfalls of an uncritical perspective on social capital. Some of the literature on social capital and health presents a romantic view of community and assumes that close knit communities are necessarily healthy. However, it is possible that they can be exclusionary and distrustful of outsiders, and may not be healthy for those who are not part of them or those within them who disagree with the majority. Similarly, there are dangers that the promotion of social capital may be seen as a substitute for economic investment in poor communities, particularly by those governments who wish to reduce government spending on welfare. None of these complexities are new. They have been part of debates about community development since at least the 1960s and 1970s. In adopting the new language of social capital it is important to learn from the lessons from previous experiments with community involvement. Engaging with social capital places an onus on public health researchers to ensure that in making the link between social capital and health they also emphasise the complexity of the relation and canvass the likely implications for social and economic policies.

New research is suggesting that analysis of comparative income distribution between countries ${ }^{7}$ and between regions within countries ${ }^{8}$ indicates that relative equity in distribution of income leads to better life expectancy. There is some indication that those states with lower income equity also have lower levels of social trust and voluntary activity and that this may account for the lower life expectancies. ${ }^{9}$ While there is some debate about the strength of the relation of the link between inequitable distribution of incomes and health,$^{10}$ the emerging evidence is worthy of serious consideration and certainly indicates the need for further investigation of relations between inequities, social capital, and health. Our theoretical understanding of why these factors might be connected is very crude and limited. One of the undisputed findings from Wilkinson's work is that there is no direct correlation between gross national product per capita and life expectancy in developed countries. Information from studies of how some low income countries, such as Cuba, China, Costa 
Rica, Sri Lanka and Kerela State in southern India, have achieved high health status ${ }^{11}$ together with the historical analysis of the importance of government action in regulating the impact of rapid industrial growth in 19th century Britain ${ }^{12}$ also indicate that economic growth alone will not lead to health improvement. These case studies portray a complex picture of interplays between economic and social factors and the role of government policies in producing health. They certainly are a warning against any simplistic interpretation of either social or economic factors in determining population health outcomes and demonstrate the value of case studies to understanding the labyrinth of population health determinants.

Understanding the complexity of social capital and its relation with economic development will be essential to the public health agenda in the next century. Most crucial will be a far more sophisticated understanding of how macro-economic policies shape the quality of social relationships between citizens, determine the levels of trust people have in each other and in their civic institutions and govern the extent to which people perceive their societies to be fair. It is also important to understand how social factors affect economic development and how the synergy between the two affects health. These complex relations are invisible determinants of our life chances and health status and much less readily understood than behavioural risk factors. But their invisibility and complexity should not be an excuse for ignoring them. Crafting a public health agenda for change that is based on solid theoretical and epidemiological understanding of the relation between social capital, economic development, public policy and health is shaping up as essential if overall health status is to be improved in a way that promotes equity.

FRAN BAUM

Department of Public Health, The Flinders University of South Australia, GPO Box 2100, Adelaide, SA 5001, Australia

1 Baum F. The new public health: an Australian perspective. Melbourne: Oxford University Press, 1998

2 Putnam RD, Leonardi R, Nanette RY. Making democracy work: civic traditions in modern Italy. New Jersey: Princeton University Press, 1993.

3 Lenci S. Social capital? From pizza connection to collective action. An inquiry into power, culture and civil society. The Hague: Netherlands Institute of Social Studies, 1998:24.

4 Seedhouse D. Health promotion: philosophy, prejudice and practice. Chichester: John Wiley, 1997.

5 Bunton R, MacDonald G, eds. Health promotion: disciplines and diversity. London: Routledge, 1992.

6 Hariss J, de Renzio P. Missing link or analytically missing: the concept of social capital fournal of International Development 1997;9:919-37.

7 Wilkinson R Unhealthy societies: the afflictions of inequalities. London: Routledge, 1996.

8 Kennedy BP, Kawachi I, Prothrow-Stith D. Income distribution and mortality: cross sectional ecological study of the Robin Hood index in the United States. BMF 1996;132:1004-7.

9 Kawachi I, Kennedy BP. Socioeconomic determinants of health: health and social cohesion: why care about income inequality? BMF 1997;314:103740.

10 Judge $\mathrm{K}$, Mulligan JA, Benzeval $\mathrm{M}$. Income inequality and population health. Soc Sci Med 1998;46:567-79.

11 Caldwell J. Routes to low mortality in poor countries. Population and Development Review 1986;12:171-220.

12 Szreter S. Mortality and public health. In: Digby A, Feinstein C, Jenkins D. New directions in economic and social history. London: MacMillan, 1992. 